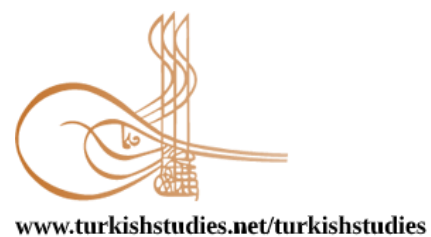

Turkish Studies

\title{
İşgören Seçiminde Makine Öğrenmesi ve Çok Kriterli Karar Verme Yöntemlerinin Birlikte Kullanımının Değerlendirilmesi
}

\author{
Evaluating the Combination of Machine Learning and Multi-Criteria Decision Making Methods in \\ Employee Selection
}

\author{
Eyüp Çalık
}

\begin{abstract}
Employee selection is one of the most important problems in the recruitment process of companies. Because selecting the right candidate among many applications for a single position can cause a long time and a high cost. Therefore, this is a process that needs to be carried out carefully, especially for companies operating in sectors with a high turnover rate and having a large number of employees. In this context, in addition to the classical methods used in employee selection, multi-criteria decision making (MCDM) methods are widely used in the literatüre while the use of prediction models with machine learning algorithms has increased significantly in recent years. However, while there is no national publication in which MCDM and machine learning methods are discussed together in employee selection, in international literature, machine learning methods are generally considered as inputs of MCDM methods, but there is no study in which the results are compared. Therefore, within the scope of this study, the question of how these two approaches can be combined in employee selection theoretically has been tried to be answered by examining the employee selection literature. As a result of the evaluations, it was concluded that MCDM and machine learning methods can be used as 4 different alternatives in employee selection problems. Therefore, with these alternative approaches, both a data-driven and a predictive approach will be used in employee selection. The results are expected to enable researchers in this field and recruitment professionals practitioners to handle employee selection problems with a novel viewpoint.
\end{abstract}

Structured Abstract: Employee selection is one of the important stages for businesses in terms of human resources management. Selecting the most suitable candidate is one of the most important problems encountered in human resources management, since there are many applications for a single position and the selection of the right candidate from the candidate pool causes a long time and a high cost. To ensure that the right candidates are recruited, it is important to use prediction models created with decision making and machine learning methods instead of classical candidate selection methods. Therefore, the existence of a good prediction model for employee selection helps to save resources, time, and money, thus enabling interviews only with candidates who are loyal to the company and perform well in the workplace (Isson ve Harriott, 2016:82). In addition, considering the literature for employee selection, while it is seen that the studies using multi-criteria decision-making (MCDM) techniques are more prominent and many studies have been done using these methods, it is observed that there are less studies using machine learning methods and

\footnotetext{
* Dr. Öğr. Üyesi, Yalova Üniversitesi, Mühendislik Fakültesi, Endüstri Mühendisliği Bölümü Asst. Prof., Yalova University, Enginireeng Faculty, Industrial Engineering Department ORCID 0000-0002-1653-4598 ecalik@yalova.edu.tr

Cite as/ Atıf: Çalık, E. (2021). İşgören seçiminde makine öğrenmesi ve çok kriterli karar verme yöntemlerinin birlikte kullanımının değerlendirilmesi. Turkish Studies, 16(5), 1483-1494. https://dx.doi.org/10.7827/TurkishStudies.51593

Received/Geliş: 31 May/Mayıs 2021

Accepted/Kabul: 25 October/Ekim 2021

Published/Yayın: 30 October/Ekim 2021

Checked by plagiarism software

CC BY-NC 4.0
} 
combined studies. Furthermore, there has been no study to indicate how MCDM and machine learning methods are combined with different alternative approaches in employee selection. To fill this gap, the main purpose of this study is considered as identifying how machine learning and MCDM methods can be combined with different approaches and to provide a basis for studies to be done on this subject.

In the employee selection literature, it seems that many studies have been conducted using MCDM techniques such as AHP, ANP, PROMETHEE, TOPSIS, ELECTRE, VIKOR individually or integrated. As a current example, Dahooie et al. (2018) performed competency-based IT personnel selection with a hybrid method combining SWARA and ARAS-G methodology, and Krishankumar et al. (2020) used the heuristic fuzzy VIKOR method. Moreover, in the studies using machine learning methods in employee selection, a decision tree algorithm was used for the selection of academic staff (Shehu \& Saeed, 2016) and Pessach et al. (2020) used the Variable-Order Bayesian Network (VOBN) method can be given as an example. Since it is a recent research area, the number of studies dealing with both approaches on this subject is much less and much more recent compared to studies that deal with these approaches individually. On the other hand, since it is a recent research area, the number of studies dealing with both approaches on this subject is much less and much more recent compared to studies that deal with these approaches individually. However, while there is no national publication in which MCDM and machine learning methods are discussed together in employee selection, in international literature, machine learning methods are generally considered as inputs of MCDM methods, but there is no study in which the results are compared.

The findings of the study indicate that the decision makers can be used with the following four different approaches while examining the studies in the literature on using MCDM and machine learning methods together for employee selection:

1. First, using the output obtained by using machine learning methods (criteria extraction, matrix creation, etc.) as an input to MCDM methods, sequentially.

2. First, using the output obtained by using MCDM methods (criteria determination, class determination, etc.) as an input to machine learning methods, sequentially.

3. Using MCDM methods to compare the predictive performance of machine learning methods.

4. Using MCDM and machine learning methods in individual employee selection, considering their results together and / or comparing them.

Among these alternatives, especially the approach of comparing the results by directly using both approaches discussed in the last alternative in the selection of candidates is one of the most important evaluations of the study and it is thought to attract the attention of both researchers and HR managers.

In employee selection problems, proposed alternatives approaches can be used by the decision maker in accordance with the company's data analytics culture and recruitment strategies. If there is enough data regarding the previously performed recruitments regarding the criteria determined for that position in the company, employee selection can be made with machine learning methods as well as MCDM methods and the results can be compared. Therefore, a data-oriented and predictive approach will be used together with these alternative approaches in employee selection. This will only be possible with a well-designed decision support software. In addition, as an important point, organizations will help to create sufficient data for the use of machine learning methods by recording new information for each recruitment into the HR database with this perspective. Therefore, it will be encouraging for the policies of SMEs on data recording and storage, with the recording of data related to HR in general, and particularly recruitment.

Keywords: Employee Selection, MCDM, Machine Learning, Human Resources Analytics, Recruitment.

Öz: İşgören seçimi, firmaların işe alım sürecindeki en önemli problemlerinden biridir. Çünkü tek bir pozisyon için çok sayıda başvuru içerisinden doğru adayın seçilebilmesi, uzun bir süreye ve yüksek bir maliyete sebep olmaktadır. Dolayısıyla özellikle işgücü devir oranı yüksek olan sektörlerde faaliyet gösteren ve çok sayıda çalışana sahip firmalar için bu durum, dikkatli yürütülmesi gereken bir süreçtir. Bu bağlamda, işgören seçimde kullanılan klasik yöntemlerde yanı sıra, bu amaçla çok kriterli karar verme (ÇKKV) yöntemleri yaygın olarak literatürde yer bulurken, makine öğrenmesi algoritmaları ile oluşturulan tahmin modellerinin kullanılması da son yıllarda dikkate değer bir şekilde artmaktadır. Bununla birlikte işgören seçiminde ÇKKV ile makine öğrenmesi yöntemlerinin birlikte ele alındığı ulusal bir yayın bulunmazken, 
uluslararası düzeydeki çalışmalarda ise genel olarak makine öğrenmesi yöntemlerinin ÇKKV yöntemlerinin girdisi şeklinde ele alınmış ancak sonuçlarının karşılaştırılarak kullanıldığı bir çalışmaya rastlanmamıştır. Dolayısıyla, bu çalışma kapsamında işgören seçimi literatürü incelenerek, kuramsal olarak bu iki yaklaşımın işgören seçiminde birlikte nasıl kullanılabileceği sorusu cevaplanmaya çalışılmıştır. Yapılan değerlendirmeler sonucunda, ÇKKV ve makine öğrenmesi yöntemlerinin işgören seçimi problemlerinde 4 farklı alternatif şeklinde kullanılabileceği sonucuna ulaşılmıştır. Dolayısıyla bu alternatif yaklaşımlarla işgören seçiminde hem veri odaklı hem de tahmine dayalı bir yaklaşım iç içe kullanılmış olacaktır. Elde edilen sonuçların bu alandaki araştırmacılara ve işe alım profesyonellerine, işgören seçimi problemlerine yeni bir yaklaşım ile bakabilmelerini sağlaması beklenmektedir.

Anahtar Kelimeler: İşgören Seçimi, ÇKKV, Makine Öğrenmesi, İnsan Kaynakları Analitiği, İşe Alım.

\section{Giriş}

İşören seçimi insan kaynakları yönetimi açısından işletmeler için önemli aşamalardan biridir. Çoğu zaman tek bir pozisyon için çok sayıda başvuru olması ve doğru adayın aday havuzundan seçilmesi, uzun bir süreye ve yüksek bir maliyete sebep olmaktadır. Bundan dolay1 pozisyona en uygun adayın seçimi, insan kaynakları yönetiminde karşılaşılan en önemli problemlerden biridir. İş ilanının verilmesinden pozisyona uygun adayın işe yerleştirilerek ilanın yayından kaldırılmasına kadar geçen bu süreç, pozisyonun doldurulma süresi olarak önemli bir insan kaynakları (IK) metriğine (bir pozisyonun ortalama doldurulma süresi-average time to fill the position) dönüşerek, şirket İK performansının izlenmesinde önemli bir İK performans göstergesi olarak kullanılmaktadır. Aynı zamanda bu sürenin uzaması, işe alım maliyetini de doğrudan etkilemektedir. Bu da benzer şekilde, bir diğer önemli İK metriğinin (bir pozisyonun ortalama doldurulma maliyeti-average cost to fill the position) insan kaynakları performansı açısından izlenmesini gerekli kılmaktadır. Aynı zamanda, Harvard Business Review'e göre, işgücü devrinin yüzde 80'inin sebebini yanlış işe alım kararları olarak değerlendirmekte ve İK Yönetimi Derneği, bu yanlış kararların maliyetinin, işgörenin yıllık maaşının beş katına kadar ulaşabileceğini öngörmektedir (Isson \& Harriott, 2016:82).

Diğer yandan, ülkemizdeki şirketlerin işgücü devir oranına bakıldığında, PERYÖN tarafından gerçekleştirilen "2018 Yılı Genel Çalışan Devir Oranı” araştırmasına katılan firmaların verdiği bilgilere göre, yıllık ortalama işgücü devir oranı \%24,45 olarak tespit edilmiştir. Yani her 4 çalışandan biri işten ayrılmaktadır. Bir başka deyişle bu oran, her dört yıl sonunda şirketlerin çalışan profilinin değişeceğine ve yenileneceğine işaret etmektedir. Aynı zamanda bu oran sektörel ve bireysel anlamda farklılık göstermektedir. Yine bu araştırmaya göre, en yüksek orana sahip sektörler inșaat ve perakende sektörleri iken en düşük orana sahip sektörler ise otomotiv ve eğitim sektörleri olarak gözlemlenmiştir (PERYÖN, 2018). Bir firmadaki işgücü devir oranının yüksek olması hem kurumsal hem de bireysel açıdan birçok konuda olumsuz etkiye sebep olmasından dolayı yüksek işgücü devir oranını engelleyebilmenin en önemli ayağı girdi kalitesini arttırabilmek, yani doğru adayları işe almaktır. Doğru adayların işe alınmasını sağlamak için klasik aday seçim yöntemlerinin yerine, karar verme ve makine öğrenmesi yöntemleri ile oluşturulan tahmin modellerinin kullanılması önem arz etmektedir. Bundan dolayı, kurumların sadece kısa dönemli değil uzun vadeli başarılı olabilmeleri için yetenek yatırımlarını bilgece yapmasını sağlamak amacıyla bu tahmin modellerinin kullanımı oldukça kritik bir öneme sahiptir. Dolayısıyla işgören seçimi için iyi bir tahmin modelinin varlı̆̆ kaynaklardan, zamandan ve paradan tasarruf edilmesine yardımcı olur, böylelikle yalnızca işe alındığında şirkete sadakati yüksek ve işyerinde iyi performans gösteren adaylar ile mülakat yapılmasına imkân sağlanır (Isson \& Harriott, 2016: 82). Ayrıca, tahmine dayalı analiz, şirketlerin hedef kitlelerine ulaşmalarını, en iyi adayları seçmeleini ve yanlış işe alım kararlarının maliyetlerinden kaçınmalarını sağlama yollarından biri olarak yeni işe alım stratejilerinin temelini oluşturmaktadır (Isson \& Harriott, 2016: 179). Bundan dolayı, veri analitiği ve makine öğrenmesi yöntemlerinin insan kaynakları verileri üzerinde kullanılarak tahmin 
yapılması ile iş değeri elde edilmesi anlamına gelen İK analitiği (Demir \& Çalık, 2020: 3748), işe alım ve seçme amaçlı stratejik bir bileşen olarak kabul edilmelidir (Momin \& Mishra, 2015: 3). Bir başka deyişle, İK analitiği kapsamında, işe alım tahmini modellemesi ile işgören seçiminde ön değerlendirme veya nihai işe alım kararlarında makine öğrenmesi yöntemleri kullanılarak kurum için en uygun adayların tahmin edilmesi, kurumlara katkı sağlayacak önemli bir yaklaşım olarak ele alınmalıdır. Bunun yanı sıra, işgören seçimi için literatüre bakıldığında ise AHP, ANP, PROMETHEE, TOPSIS, ELECTRE, VIKOR vb. çok kriterli karar verme tekniklerinin (ÇKKV) kullanıldığı çalışmaların öne çıktığı ve bu yöntemlerin kullanılarak birçok çalışmanın yapıldığı gözükürken, makine öğrenmesi yöntemlerinin kullanılarak yapılan çalışmaların daha az olduğu göze çarpmaktadır. Ama her iki yaklaşımın da literatürde yer bulması ve yapılan araştırmalardaki uygulama örneklerinden faydalı sonuçlarının aktarılması, bu yöntemlerin işgören seçiminde kullanılmasının önemini göstermesi bakımından dikkate değerdir.

$\mathrm{Bu}$ yöntemlerin en önemli avantajı işgören seçimi problemini analitik bir yaklaşımla ele alması olarak değerlendirilebilir. Hem ÇKKV hem makine öğrenmesi yöntemlerinin bu avantajının yanı sıra Chuang vd. (2020) işgören seçimi için kullanılan ÇKKV modellerinin uzman yargılarına dayanmasından ötürü öznellik barındırdığını ifade etmekte ve bu durumun bu tür karar verme süreci üzerinde olumsuz bir etkiye sahip olduğunu aktarmaktadır. Dolayısıyla, geçmiş verisine ihtiyaç duymama ÇKKV yöntemlerinin önemli bir artısıyken yönetsel yargılara dayanması bir dezavantaj olarak görülmektedir. Makine öğrenmesi yöntemlerinin de en temel handikabı, tahminde kullanılacak geçmiş verinin yeterli miktarda ve kalitede olmaması olarak ifade edilebilir. $\mathrm{Bu}$ açıdan değerlendirildiğinde, iki yöntemin birlikte ele alınması bu avantaj ve dezavantajları bir dengeye oturtulması açısından önemlidir ve Chuang vd. (2020) de veriye dayalı makine öğrenmesi algoritmaları ile ÇKKV yöntemlerinin birlikte ele alınmasını gerektiğini vurgulamıştır.

$\mathrm{Bu}$ çalışmanın temel amacı, işgören seçiminde iş değeri oluşturan makine öğrenmesi ve ÇKKV yöntemlerinin birlikte farklı yaklaşımlarla nasıl ele alınabileceğini göstermek ve bu konuda yapılacak çalışmalara temel oluşturmak için teorik bir çerçeve sunmaktır. Bu bağlamda, diğer klasik işe alım yöntemlerine değinmeden, işgören seçimi için önce çok kriterli karar verme yöntemlerini kullanan araştırmalardan ve sonrasında makine öğrenmesi yöntemleriyle bu probleme yaklaşan çalışmalardan bahsedilecektir. Sonrasında ise bu iki yaklaşımın işgören seçiminde nasıl ele alındığı ve farklı yaklaşımlarla nasıl ele alınabileceği değerlendirilecektir. Son kısımda ise, elde edilen bulgular özetlenerek aktarılacaktır.

\section{İşgören Seçiminde ÇKKV Yöntemlerinin Kullanılması}

Literatürde, işgören seçiminde ÇKKV yöntemleri kullanan çalışmalar oldukça fazla olduğundan hepsinden bahsetmek çalışmanın amacı ve kapsamı dışına çıkmak olacaktır. Bu sebeple, çalışmanın hedefine yönelik olarak ÇKKV yöntemlerini kullanan, öncelikle uluslararası çalışmalardan farklı yöntemlerin kullanıldığ yapılan çalışmalardan da yine güncel örneklerin bir kısmına değinilecektir. Bu bağlamda, Afshari vd. (2010) yaptıkları araştırmada, basit eklemeli ağırlıklandırma yöntemi ile kriter ağırlıklandırma yaparak, personel seçimi probleminde kullanmışlardır. Benzer şekilde, personel seçimi ile ilgili yapılan çalışmalara, Zhang ve Liu (2011) tarafından GRA temelli sezgisel bulanık çok kriterli grup karar verme yöntemi ve Chen vd. (2011) tarafindan Dilsel VIKOR ve bilgi haritası yöntemleri kullanılan bu araştırmalar örnek verilebilir. Daha güncel bir örnek olarak, Salehi (2016) personel seçim problemine yönelik olarak bulanık AHP ve bulanık VIKOR'un entegre edilmesi ile ettiği bütünleşik yaklaşım içeren bir model kullanmıştır. Personel seçimi sorununu ele alan güncel çalışmalardan bir diğerinde ise, bulanık ELECTRE yöntemi kullanılmıştır (Jasemi \& Ahmadi, 2018). Diğer bir çalışmada ise, Dahooie vd. (2018) yetkinlik bazlı IT personel seçimini, SWARA ve ARAS-G metodolojisini birleştiren hibrit bir yöntem ile gerçekleştirmiştir. Son olarak, çok daha güncel bir çalışmada, işgören seçimi problemini çözmek için sezgisel bulanık VIKOR yöntemi kullanılmıştır (Krishankumar vd., 2020). 
Öte yandan, işgören seçimi için çok kriterli karar verme yöntemleri kullanılarak Türkiye'de yapılan çalışmalara bakıldığında da oldukça fazla çalışma olduğu görülmektedir. Bu bağlamda, farklı yöntemleri ele alan çalışmalardan ve güncel bazı araştırmalardan örnekler verilecektir. Yapılan bir çalışmada, imalat sistemlerinde personel seçimi için analitik ağ sürecini (ANP) ve modifiye edilmiş TOPSIS'i beraber içeren hibrit bir personel seçim modeli önerilmiştir (Dağdeviren, 2010). Başka bir örnek olarak ANP ve DEMATEL yöntemlerini birlikte kullanarak işgören seçimi problemini bütünleşik bir şekilde ele alan benzer bir çalışmada, DEMATEL yöntemi kullanılarak kriterler arasındaki bağımlı ağırlık değerleri belirlenmiş ve işgören seçimi için geliştirilen bu modelin çözümü ANP yöntemi ile gerçekleştirilmiştir (Aksakal \& Dağdeviren, 2010). Bunlarla birlikte, Koyuncu ve Özcan (2014) otomotiv imalat sektöründeki bir firmanın işgören seçimi için Analitik Hiyerarşi Süreci (AHP) ve TOPSIS yöntemlerini kullanmış ve edilen sıralama sonuçlarıyla çalışanların performans puanlarını karşılaştırarak, daha az sapma gösteren AHP yönteminin firma için kullanılmasını önermiştir. Bir başka çalışma da ise, araştırma görevlisi kadrosu için yapılan işe alım sürecinde bulanık TOPSIS yöntemi kullanılmıştır. Bu bağlamda, her bir aday için yakınlık katsayıları bulunarak, ele alınan kriterlere göre seçim gerçekleştirilmiştir (Akın, 2016). Diğer bir çalışmada, Kenger ve Organ (2017) çok kriterli karar verme yöntemleri kullanılarak yapılan personel seçiminin bankacılık sektöründe uygulanabilirliğini, entropi temelli ARAS yöntemi ile araştırmıştır. Bunların yanı sıra, kriterler arasındaki bağımlılı̆̆ın, ilişkinin ve çevresel belirsizliklerin belirlenmesi amacıyla Özdemir ve Nalbant (2018) genelleştirilmiş Choquet Integral yöntemini kullanarak işgören seçim problemi üzerinde uygulamıştır. Başka bir güncel çalışmada ise, Giresun ilindeki turizm otel işletmelerinin yönetici personellerinin seçiminde öncelikli olarak dikkate alınan kriterlerin belirlenmesi amaçlanan, personel seçimi kriterlerinin değerlendirilmesine yönelik bir araştırmada AHP yöntemi kullanılmıştır (Akyurt, 2019). Diğer güncel araştırmalara ise, havacılık sektöründe işgören seçimi için yapılan bulanık MULTIMOORA (Kuşakçı vd., 2019) ve ARAS yöntemi (Yıldırım vd., 2019) ile yapılan uygulama çalışmaları gösterilebilir. Son güncel örnek olarak, Demirci ve Kılıç (2019) yaptıkları çalışmada, DEMATEL, ANP ve ELECTRE yöntemlerini entegre ederek elde ettikleri ÇKKV modelini, bir imalat işletmesinin mühendis seçiminde uygulamıştır.

Yukarıda hem Türkiye'de yapılan hem de diğer uluslararası yayınlardan verilen örneklerde görüldüğü gibi çok kriterli karar verme yöntemlerinin tekil olarak veya birlikte (hibrit/bütünleşmiş) bir şekilde işgören seçiminde oldukça yoğun olarak kullanıldığ 1 ve yapılan uygulama örnekleriyle işgören seçimi sürecine yaptığı katkılar görülmektedir. Öne çıkan örnekler olarak verilen tüm bu çalışmalardan elde edilen sonuçlar düşünüldügünde, birçok kriteri bir arada düşünerek yapılan işgören seçiminde çok kriterli karar verme yöntemlerinin kullanılmasının, bu sürece önemli bir katk1 sunduğu değerlendirilebilir. Bu yöntemlerin en önemli avantajı, birçok kriterin ele alındığı işgören seçimi problemlerine analitik bir yaklaşım sunması ve yöntemler uygulanırken geçmiş işe alım verilerine ihtiyaç duymaması olarak ifade edilebilir. Bu avantajlarının yanı sıra doğrudan hangi yöntemin kullanılması gerektiği konusunda bir uzlaşının olmaması ve temelde yönetici yargısına dayanması öne çıkan dezavantajları olarak nitelendirilebilir.

\section{İşgören Seçiminde Makine Öğrenmesi Yöntemlerinin Kullanılması}

İşgören seçim problemleri makine öğrenmesi bakış açısıyla ele alındığında, aday işgörenin uygunluğunun basitçe "uygun-uygun değil" şeklinde kategorik bir hedef değişken olduğu bir sinıflandırma problemi olduğu görülmektedir. Dolayısıyla işgören seçim problemlerinde çıktı değerlerinin (değişken) "uygun-uygun değil" şeklinde ikili (binary) bir hedef değişken olarak belirlenmesi, sınıflandırma tahmin modeli için yeterlidir (Demir \& Çalık, 2020:3750). Benzer şekilde, Pessach vd. (2020) işgören seçim modelindeki hedef değişkeni, İK birimi çalışan bilgilerini temel alıp, işe alım kararını, "başarılı-başarısız" işe alımlar şeklinde değerlendirerek iki kategorili olarak belirlemiştir. Bu bağlamda, ele alınış biçimleri benzer olmakla beraber, literatürde işgören seçimde farklı makine öğrenmesi yöntemleri kullanılarak yapılan çalışmalardan öne çıkan araştırmalar aktarılacaktır. İlk olarak, bu konudaki öncü çalışmalardan biri olan, Chien ve Chen 
(2008) tarafından gerçekleştirilen bir araştırmada, personel seçimi için birliktelik kuralları ve karar ağacı algoritmalarını kullanan bir model geliştirilmiş̧tir. Bu modelde personele ait yaş, deneyim vb. 8 öznitelik kullanılarak CHAID algoritması yardımıyla işgören seçimi gerçekleştirilmiştir. Diğer yandan, Jantan vd. farklı yıllardaki konferanslarda sundukları bildirilerinde, makine öğrenmesi algoritmalarının yetenek yönetiminde kullanılabileceğini belirtmişler ve yetenek tahmini için karar ağacı, yapay sinir ağları vb. algoritmaları kullanmışlardır (Jantan vd., 2009, 2011). Başka bir çalışmada ise, karar ağacı algoritması içeren bir model oluşturularak akademik personelin seçimi için kullanılmıştır (Shehu \& Saeed, 2016). Daha güncel bir araştırmada, aday seçiminde çeşitli makine öğrenmesi teknikleri kullanılarak bir tavsiye modeli geliştirilip, şirketin kullanımına sunulmuştur (Shehu \& Besimi, 2018). Çok daha güncel bir örnek olarak, Pessach vd. (2020), tarafından 2000-2010 yılları arasında işe alınan çalışanların çeşitli bilgileri (eğitim durumu, yaş, test puanları vb.) kullanılarak işe alım modellemesi yapılmış ve Variable-Order Bayesian Network (VOBN) yöntemi yardımıyla işgören seçimi gerçekleştirilmiştir. Son olarak ulusal yayınlara bakıldığında ise, Demir ve Çalık (2020) tarafından işgören seçiminde örnek bir vaka üzerinde alternatif makine öğrenmesi yöntemleri uygulanarak, Ar-Ge personelinin seçilmesinde adayların işe uygunluğu tahmin edilmiş ve ele alınan kriterlerin önem dereceleri de elde edilmiştir. Tüm bu çalışmalara bakıldığında, makine öğrenmesi yöntemlerinin kullanılabilmesi için, geçmiş işe alım ile ilgili bilgilerin yeterli miktarda ve kalitede olması en önemli gereklilik olarak öne çıkmaktadır. Aynı zamanda bilişim teknolojilerindeki gelişmenin büyük miktarda verinin elde edilmesi ve işlenmesine olanak sağlaması, bu algoritmaların insan kaynakları uygulamalarında kullanımına imkân vermektedir. Bu şekilde bir verinin olmadığı durumlarda her ne kadar güncel ve tahmin odaklı bir yaklaşım da olsa işgören seçim problemlerinde bu algoritmaların kullanılması mümkün olmayacağından dolayı bu yöntemlerin uygulamadaki en temel kısıtının bu olduğu ifade edilebilir.

\section{Makine Öğrenmesi ve ÇKKV Yöntemlerinin Birlikte Kullanılması}

Makine öğrenmesi ve ÇKKV yöntemlerinin ayrı ayrı işgören seçiminde kullanılması ile ilgili literatürde öne çıkan araştırmalar aktarıldıktan sonra bu kısımda, bu iki yaklaşımı birlikte ele alan çalışmalara değinilecektir. Güncel bir araştırma alanı olduğu için bu konuda her iki yaklaşımı birlikte ele alan çalışmaların sayısı, bu yaklaşımları tekil olarak ele alan çalışmalara göre oldukça azdır ve çok daha günceldir. Bu bağlamda, Chuang vd. (2020) işgören seçimi için önceden geliştirilen ÇKKV modellerinin girdi olarak uzman yargılarına dayandığı için uzman deneyimlerinin öznelliğinin, bu tür karar verme süreci üzerinde olumsuz bir etkiye sahip olduğunu ifade etmişler ve günümüzün veriye dayalı karar alma ortamının gelişimiyle birlikte, yöneticilerin personeli daha objektif bir şekilde seçmelerine yardımcı olmak ve yetkinlik gelişimlerini desteklemek için makine öğrenimi ve ÇKKV yöntemlerini entegre eden veriye dayalı bir ÇKKV modeli geliştirmiştir. Bu modelde makine öğrenmesi yöntemlerinden kaba küme teorisini (Rough set theory-RST) kullanılarak gerçek değerlendirme verilerinden ilk etkili önem-ilişki matrisi elde edilmiş ve daha sonra ilk matristen etkili bir anlamlılık ağı ilişki haritası ve etkili ağırlıkları türetmek için Dematel ANP (DANP) yöntemi kullanılmıştır. Son kısımda ise, adayları değerlendirmek için PROMETHEE-AS yöntemi uygulanmıştır. Yani makine öğrenmesi yöntemlerinden kaba küme teorisi, DANP ve PROMETHEE-AS'ye birer girdi olarak verilerek sırasal bir şekilde makine öğrenmesi algoritması, ÇKKV yöntemleri için bir girdi olacak şekilde kullanılmıştır. Başka bir çalışmada, Maghsoodi vd. (2020) mega yapılı organizasyonlarda, personel seçimi prosedürünün çeşitli alt bölümlerde ve departmanlarda iş pozisyonları için potansiyel adayların sayısı nedeniyle büyük veri yapıları içerdiğini, bu nedenle, bu tür ortamlarda personel seçimi sorununun, zamandan ve maliyetten tasarruf etmek için ihtiyatla ele alınması gereken bir büyük veri sorunu olarak düşünülmesi gerektiğini ifade etmiştir. Bu amaçla yaptıkları çalışmada, doğrudan sınıflandırma algoritmaları kullanmamışlar ancak kümeleme analizini ÇKKV yöntemleriyle birlikte kullanan CLUS-MCDA yaklaşımını genişleterek bunu En İyi-En Kötü Yöntem (BWM) yaklaşımına entegre edip, bu çok senaryolu büyük veri kararını çözmek için kullanmıştır. Diğer yandan, Li vd. (2011) kişilik testleri yardımıyla adayların hangi birime daha 
uygun olduğunu belirlemek amaciyla uygunluk skorunu tahmin etmek için Destek Vektör Makineleri (SVM) kullanmış, bu uygunluk skorunu da diğer kriterlerle beraber işe yerleştirme performansını tahmin etmek için TOPSIS yöntemine girdi olacak şekilde ele almıştır. Bu çalışma, her ne kadar farklı departmanlarda istihdam durumunun kısıtlı sayıda pozisyon için kullanılabilecek bir yaklaşıma sahip olsa da işgören seçiminde makine öğrenmesi yöntemlerinin çıktısının ÇKKV yöntemlerine girdi olarak ele alındığı sırasal kullanıma bir örmek olarak verilebilir. Dolayısıyla bu açıklamalar ışığında birinci alternatif şu şekilde yazılabilir:

Alternatif-1. Önce makine öğrenmesi yöntemlerini kullanarak elde edilen çıktının (kriter çıkarımı, matris oluşturma, vb.) ÇKKV yöntemlerine girdi olarak, sirasal bir şekilde kullanılmast.

$\mathrm{Bu}$ alternatif yaklaşımın en önemli avantajı, ÇKKV yöntemlerinin girdi matrislerinin veriye dayalı olarak makine öğrenmesi algoritmaları kullanılarak üretilmesi olarak ifade edilebilir. Ancak yukarıda belirtildiği gibi yeterli miktarda ve kalitede verinin bulunmaması yine bu yaklaşımın temel kısıtını oluşturacaktır. Bununla birlikte, her ne kadar çok fazla örnek olmasa da literatürde işgören seçimi için bu iki yaklaşımın birlikte ele alındığı çalışmaların genel olarak Alternatif-1 olarak benimsendiği gözükmektedir.

Öte yandan, literatürde işgören seçimi dışında gerek İK uygulamalarında veya başka alanlardaki karar verme problemlerinde ÇKKV yöntemleri ile makine öğrenmesi algoritmalarının farklı yaklaşımlarla birlikte ele alındığı çalışmalara rastlanılmaktadır. Bu yaklaşımlar irdelenerek işgören seçiminde bu iki yaklaşımın farklı şekillerde kullanımları için diğer alternatifler ortaya konulacaktır. Bu bağlamda, Jain vd. (2021) tarafından yapılan oldukça güncel bir çalışmada, İK uygulamaları bağlamında kayıp çalışan tahmini için makine öğrenmesi ve ÇKKV yöntemleri entegre edilerek kullanılmıştır. Bu araştırmada kayıp çalışan sınıflarını belirlemek için önce ÇKKV yöntemlerinden entropi ağırlık ve TOPSIS kullanılmış daha sonra makine öğrenmesi algoritmaları kullanılarak sınıf tahmini yapılmıştır. Bununla birlikte, Putra vd. (2016) tarafından yapılan çalışmada, bursiyer seçiminde sırasal olarak AHP-SVM-TOPSIS yöntemleri art arda kullanılarak bir seçim ve tavsiye sistemi geliştirilmiştir. AHP yöntemi ana kriterleri belirlemek için kullanılmış, daha sonra SVM bu kriterleri kullanarak sınıf tahmini yapmış ve TOPSIS'e girdi olarak vermiştir. $\mathrm{Bu}$ örnek çalışmalarda görüldüğ̈̈ gibi, ele alınan iki yaklaşımın önce ÇKKV sonra makine öğrenmesi şeklinde de sırasal olarak girdi-çıktı ilişkisi şeklinde ele alınabileceğini göstermektedir. Dolayısıyla, ikinci alternatif aşağıdaki şekilde ifade edilebilir:

Alternatif-2. Önce ÇKKV yöntemlerini kullanarak elde edilen çıktının (kriter belirleme, sinif belirleme, vb.) makine öğrenmesi yöntemlerine girdi olarak, sirasal bir şekilde kullanılmasi.

İkinci alternatif yaklaşımında ÇKKV yöntemleri, sınıfları yani hedef değişkeni veya bu sınıfları tahminde kullanılacak kriterleri yani öznitelikleri belirlemede kullanılmak istendiğinde, birçok kriter içerisinde yeteri kadar veri olmadığ 1 durumlarda hangi kriterlerin daha önemli olduğunu belirlemek ve o şekilde modelleme yaparak makine öğrenmesinde kullanmak amacı çerçevesinde ele alınması anlamlı olacaktır. Dolayısıyla bu yaklaşım ile gereksiz veri toplanmasının önüne geçilmiş olacak ve daha az değişken ile modelleme yapılabilecektir. Ancak burada unutulmaması gereken bir nokta, ÇKKV yöntemlerinin barındırdığı öznelliğin bu kriterlerin belirlenmesinde de etkili olacağıdır.

Diğer bir alternatif olarak, literatürde yaygın olarak karşılaşılmasa da bu iki yaklaşımın birlikte farklı bir kullanımı açısından örnek olarak verilebilecek bir çalışmada, Wang vd. (2010) Çin'deki büyük bir ticari bankanın kredi kartı sahiplerinin davranışlarını 12 sınıflandırma algoritması uygulayarak tahmin etmişler ve PROMETHEE II ve TOPSIS gibi çok kriterli karar verme tekniklerini kullanarak sınıflandırma algoritmalarının öngörücü performanslarını, doğruluk oranı, AUC, kesinlik, hassaslık ölçütü, eğitim ve test süresi vb. 8 kriter kullanarak karşılaştırmıştır. 
Doğrudan işgören seçimi için bu şekilde bir kullanıma literatürde karşılaşılmasa da benzer şekilde işgören seçiminde kullanılan makine öğrenmesi yöntemlerinin performansını değerlendirmek için de kullanılabilir. Dolayısıyla diğer bir alternatif aşağıdaki şekilde belirlenmiştir:

Alternatif-3. Makine öğrenmesi yöntemlerinin tahmin performanslarını karşılaştırma amacıyla ÇKKV yöntemlerinin kullanılması.

$\mathrm{Bu}$ alternatifin yaygın olarak kullanılmamasının nedeni, tahmin yöntemlerinin performanslarının karşılaş̧ırılmasında sınıflandırma başarısının yanı sıra kullanılan hassaslık, süre vb. kriterlerin vaka spesifik olarak yorumlanması gerekliliği olarak düşünülebilir. Yani sınıflandırma başarısının doğrudan önemli olduğu vakaların yanı sıra diğer değerlendirme ölçütlerinin daha önemli olduğu ve doğrudan o ölçüte göre karar vermenin gerekli olduğu durumlarda, ÇKKV yöntemlerine ihtiyaç duyulmadığı şeklinde düşünülebilir. Ayrıca, İK uygulamalarındaki verinin göreceli olarak kısıtlı olması, işgören seçiminde ele alınacak modellerin daha az karmaşık olması ve veri işleme teknolojilerinin kapasitelerinin artmasından dolayı özellikle eğitim ve test süresi kriterinin önemini azaltmaktadır.

Ele alınan bu üç alternatif yönteme bakıldığında, Alternatif-1 olarak ele alınan çalışmalarda makine öğrenmesi yöntemleri, ara yöntem ve girdi olarak, ÇKKV yöntemlerine entegre edilmiş ve doğrudan uygun aday sınıflandırılmasında kullanılmamıştır. Alternatif-2 ve Alternatif-3'te ise makine öğrenmesi algoritmaları, işgören seçiminde doğrudan kullanılarak sınıflandırma tahmini yapılması şeklinde ele alınmıştır. Öte yandan, işgören seçiminde çok kriterli karar verme yöntemleri ile makine öğrenmesi yöntemlerinin birlikte ele alındığı, ulusal olarak herhangi bir yayın bulunmazken, bahsi geçen oldukça güncel iki çalışmanın dışında uluslararası yayınlarda ise makine öğrenmesi yöntemlerinin doğrudan aday tahmininde kullanılarak ÇKKV yöntemleri ile birlikte ele alınıp, sonuçlarının karşılaştırıldığı bir çalışmaya rastlanmamaktadır. Bunun nedeni, konunun güncel olmasının yanı sıra çok kriterli karar verme yöntemleri temelde uzman görüşüne dayanırken, makine öğrenmesi yöntemlerinin kullanılmasının ise, firmadaki önceki işe alım verilerinin bulunması ve modellenerek işgören seçiminde kullanılması temeline dayanması olarak düşünülebilir. Ancak hem önceki işe alım verilerinin var olduğu ve hem de işe alım karar vericilerin görüşlerini temel alan bir vaka için bu iki farklı yaklaşımın sonuçları karşılaştırılarak da kullanılabilir. Dolayısıyla çok kriterli karar verme teknikleri ve makine öğrenmesi algoritmaları diğer alternatiflerde olduğu gibi entegre edilerek kullanılabileceği gibi, karşılaştırma yapmak için de kullanılması mümkündür. Eğer firmanın önceki işgören seçimleriyle ilgili yeterli verisi varsa, bu iki farklı yaklaşım ayrı ayrı aday sıralama ve tahmininde kullanılıp, sonuçlar karşılaştırılarak veya birlikte ele alınarak karar vericiye sunulabilir. Örneğin önce makine öğrenmesi yöntemleri olarak adayların uygunluğu tahmin edilip, daha sonra sadece uygun olan adaylar ÇKKV yöntemleri kullanarak sıralanabilir ve seçilebilir. Bu bağlamda son alternatif şu şekilde yazılabilir:

Alternatif-4. ÇKKV ve makine öğrenmesi yöntemlerinin ayrı ayrı işgören seçiminde kullanılarak sonuçlarının birlikte ele alınarak ve/veya karşılaştırılarak kullanılması.

$\mathrm{Bu}$ son alternatifte aday uygunluğunun farklı yöntemlerle karşılaştırılabilmesi en önemli avantaj olarak öne çıkarken, ÇKKV yöntemlerinin öznelliğine de bir seviyede cevap verilmiş olacaktır. Ancak önceki kısımlarda da aktarıldığ 1 üzere, yeteri miktar ve kalitede verinin olmadığ durumlarda bu alternatifin de kullanılması mümkün olmayacaktır. Ayrıca, Putra vd. (2016) tarafından yapılan bursiyer seçimiyle ilgili çalışmada, AHP-SVM-TOPSIS yöntemlerinin sırasal olarak art arda kullanılması gibi -ki bu yaklaşım ilk iki alternatifi de içermektedir- bu son alternatif için de düşünülebilir. Önce kriter belirleme vb. için bir ÇKKV yöntemi kullanıp, o kriterleri temel alarak hem makine öğrenmesi yöntemleri kullanılarak işgören seçimi yapılıp, hem de yine aynı kriterler referans alınarak başka bir ÇKKV yöntemi ile aday uygunlukları belirlenip karşılaş̧tırılabilir. Sonuç olarak, her bir alternatifte, ÇKKV ve makine öğrenmesi yöntemlerinin ne amaçla kullanıldığı ve birlikte nasıl ele alındığı Tablo 1'de özetlenmiştir. 
Tablo 1: Alternatiflerin Kullanımı

\begin{tabular}{llll}
\hline Alternatif & ÇKKV & Makine Öğrenmesi & Kullanım Türü \\
\hline \multirow{2}{*}{ Alternatif-1 } & İşörren Seçimi & $\begin{array}{l}\text { ÇKKV Yöntemlerine } \\
\text { Girdi Sağlama }\end{array}$ & $\begin{array}{l}\text { Sirasal } \\
\text { Girdi-Çıktı }\end{array}$ \\
\multirow{2}{*}{ Alternatif-2 } & $\begin{array}{l}\text { Makine Öğrenmesi Algoritmalarına Girdi } \\
\text { Sağlama }\end{array}$ & $\begin{array}{l}\text { İşgören Seçimi } \\
\text { Tahmini }\end{array}$ & $\begin{array}{l}\text { Sirasal } \\
\text { Girdi-Çıktı }\end{array}$ \\
Alternatif-3 & $\begin{array}{l}\text { Makine Öğrenmesi Algoritmalarının } \\
\text { Tahmin Performanslarının Karşılaştırılması }\end{array}$ & $\begin{array}{l}\text { İşgören Seçimi } \\
\text { Tahmini }\end{array}$ & $\begin{array}{l}\text { Bütünleştirmeden } \\
\text { Kullanım }\end{array}$ \\
\hline \multirow{2}{*}{ Alternatif-4 } & İşören Seçimi & $\begin{array}{l}\text { İşgören Seçimi } \\
\text { Tahmini }\end{array}$ & $\begin{array}{l}\text { Sonuçların Birlikte } \\
\text { Kullanımı }\end{array}$ \\
\hline
\end{tabular}

\section{Sonuç ve Değerlendirme}

İşören seçim problemlerinde ÇKKV ve makine öğrenmesi yöntemlerinin ayrı olarak kullanımı göreceli olarak daha eskiye dayanmaktadır. $\mathrm{Bu}$ problem, makine öğrenmesi bakış açısıyla ele alındığında, aday işgörenin uygunluğunun kategorik bir hedef değişken olarak ele alındığı bir sınıflandırma problemidir. Dolayısıyla makine öğrenmesi yöntemleri kullanılarak, yeterli miktar ve kalitede geçmiş işe alım verisinin olduğu durumlarda, bu verilere dayalı olarak, işgören adaylarının hangisinin kurum için uygun olduğu tahmini yapılmakta ve işe uygun olan adaylar seçilmektedir. Diğer yandan ÇKKV yöntemlerinin genel hedefi ise, her yöntemde farkl1 adımlar izlenmekle beraber, karar vericinin yaklaşımı temel alınarak, adayların sıralanması veya doğrudan uygun adayların seçilmesidir. Karar verici dilediği kadar adayı bu sıralamaya göre değerlendirebilir ve seçebilir. ÇKKV ve makine öğrenmesi yöntemlerinin çalışma prensipleri birbirinden farklı olmasına rağmen aynı problemlerde birlikte kullanılabileceği hem İK hem de farklı alanlardaki literatürden verilen örneklerle açıklanmıştı. Bu iki yaklaşımın işgören seçim problemlerinde birlikte nasıl kullanılabileceğinin ortaya konulması, veriye dayalı ve tahmin odaklı bir çözüm için farklı bir bakış açısı verecektir. Bu bağlamda, ÇKKV ve makine öğrenmesinin yöntemlerinin işgören seçimi için birlikte kullanılması konusunda literatürde bulunan çalışmalar irdelendiğinde aşağıdaki dört farklı yaklaşım ile karar verici tarafından kullanılabileceği şeklinde bir sonuç ortaya konulmuştur.

1. Önce makine öğrenmesi yöntemlerini kullanarak elde edilen çıktının (kriter çıkarımı, matris oluşturma, vb.) ÇKKV yöntemlerine girdi olarak, sırasal bir şekilde kullanılması.

2. Önce ÇKKV yöntemlerini kullanarak elde edilen çıktının (kriter belirleme, sınıf belirleme, vb.) makine öğrenmesi yöntemlerine girdi olarak, sırasal bir şekilde kullanılması.

3. Makine öğrenmesi yöntemlerinin tahmin performanslarını karşılaştırma amacıyla ÇKKV yöntemlerinin kullanılması.

4. ÇKKV ve makine öğrenmesi yöntemlerinin ayrı ayrı işgören seçiminde kullanılarak sonuçlarının birlikte ele alınarak ve/veya karşılaştırılarak kullanılması.

$\mathrm{Bu}$ alternatifler literatüre dayalı bir şekilde sunularak, bu iki önemli yaklaşımın işgören seçimi problemlerinde birlikte nasıl kullanılacağı konusunda teorik bir çerçeve çizilmeye çalışılmıştır. Bu alternatifler içerisinde, özellikle son alternatifte ele alınan her iki yaklaşımının aday seçiminde doğrudan kullanılarak sonuçların karşılaştırılması şeklindeki öneri gerek araştırmacıların gerek İK yöneticilerinin dikkatini çekebilecek nitelikte olduğu düşünülmektedir. Çalışma kapsamında, bu yaklaşımın kullanımını içeren bir uygulama yapılmaması, çalışmanın önemli bir kısıtı olmakla beraber bu kısıt, gelecek araştırmaları için bir altyapı sunmaktadır. Bu bağlamda, son alternatif yaklaşım kullanılarak uygulama yapılıp, sonuçları sunulabilir ve ayrıca 
diğer alternatif yöntemlerle de karşılaştırma yapılabilir. Burada kullanılacak ÇKKV yöntemlerinin veya makine öğrenmesi algoritmalarının çeşitliliği düşünüldügünde birçok farklı araştırmaya imkân sağlayacak potansiyeli barındırdığı gözükmektedir.

Ayrıca işgören seçimi problemlerinde bu alternatifler yaklaşımlar, karar verici tarafından şirketin veri analitiği kültürüne ve işe alım stratejilerine uyumlu olacak şekilde kullanılabilir. Yukarıda detaylıca ele alındığı gibi, sadece ÇKKV yöntemlerini kullanmanın öznellik barındırması sebebiyle var olan dezavantaj, veriye dayalı makine öğrenmesi yöntemleriyle beraber bütünleşmiş bir şekilde kullanılarak ortadan kaldırılmış olacaktır. Eğer firmada o pozisyon için belirlenen kriterlerle ilgili daha önce gerçekleștirilmiș ișe alımlarla alakalı yeteri miktarda ve kalitede veri varsa, bu yöntemler bütünleşik bir şekilde kullanılabileceği gibi, ÇKKV yöntemlerinin yanı sıra makine öğrenmesi yöntemleri ile de işgören seçimi yapılıp sonuçlar karşılaştırılacak şekilde de ele alınabilecektir. Dolayısıyla bu alternatif yaklaşımlarla işgören seçiminde ele alınan kriterlerin önem derecelerini göz önünde bulunduran, veriye dayalı ve tahmin odaklı bir yaklaşım iç içe kullanılmış olacaktır. Bu yaklaşımların kullanımı, karar vericilere ve İK yöneticilerine, gerçek verilerden elde edilen davranış modellerine dayalı olarak sistematik bir perspektiften işgören seçimindeki performanslarını iyileştirme için uygun bir strateji oluşturmalarına da yardımcı olacaktır (Chuang et al., 2020: 754). Öte yandan bu metotların birlikte kullanımı ancak iyi kurgulanmış bir karar destek yazılımı ile mümkün olacaktır. Bu bu bakış açısıyla tasarlanan yazılımlar, ayrıca her bir işe alım için yeni bilgileri veri tabanına kaydederek, makine öğrenmesi yöntemlerinin kullanılabilmesi için kurumların yeterli miktarda ve kalitede veri oluşturmasına da yardımcı olacaktır. Dolayısıyla genelde İK, özelde işe alım ile ilgili verilerin kaydedilmesiyle bu durum, özellikle küçük ve orta büyüklükteki işletmelerin veri kaydetme ve saklama konusundaki politikaları için teşvik edici olacaktır. Ayrıca, bu sürecin geliştirilecek yazılımlarla süre ve maliyet açısından etkin bir hale getirilmesi ve yaygın bir kullanım alanı bulması ile aday seçim süreleri kısalacaktır. Böylelikle işe en uygun adayın daha kısa bir sürede seçimi sayesinde, kurumların işe alım süreçlerinin verimlilik artışının yanı sıra aday işgören psikolojisinde gereksiz beklemelerden dolayı oluşacak yıpranmaların azalmasına olumlu bir etkisinin olacağı şeklinde bir değerlendirme yapılabilir.

\section{Kaynakça}

Afshari, A., Mojahed, M., \& Yusuff, R. M. (2010). Simple Additive Weighting approach to Personnel Selection problem. International Journal of Innovation, Management and Technology, 1(5), 511-515.

Akın, N. G. (2016). Personel Seçiminde Çok Kriterli Karar Verme: Bulanık Topsis Uygulaması. In Journal of Business Research - Turk (Vol. 8, Issue 2, pp. 224-224). https://doi.org/10.20491/isarder.2016.177

Aksakal, E., \& Dağdeviren, M. (2010). ANP ve DEMATEL yöntemleri ile personel seçi mi problemine bütünleşik bir yaklaşim. In Journal of the Faculty of Engineering and Architecture of Gazi University (Vol. 25, Issue 4, pp. 905-913).

Akyurt, H. (2019). Analitik Hiyerarşi Seçim Yöntemi ile Otel Personeli Seçimi Kriterlerinin Değerlendirilmesi: Giresun İli Örneği. IBAD Sosyal Bilimler Dergisi, 2(4), 64-78. https://doi.org/10.21733/ibad.603290

Chen, C. T., Pai, P. F., \& Hung, W. Z. (2011). Applying linguistic VIKOR and knowledge map in personnel selection. In Asia Pacific Management Review (Vol. 16, Issue 4, pp. 491-502). https://doi.org/10.6126/APMR.2011.16.4.02

Chien, C.-F., \& Chen, L.-F. (2008). Data mining to improve personnel selection and enhance human capital: A case study in high-technology industry. Expert Systems with Applications, 34(1), 280-290. https://doi.org/10.1016/j.eswa.2006.09.003 
Chuang, Y.-C., Hu, S.-K., Liou, J. J. H., \& Tzeng, G.-H. (2020). A Data-Driven MADM Model For Personnel Selection And Improvement. Technological and Economic Development of Economy, 26(4), 751-784. https://doi.org/10.3846/tede.2020.12366

Dağdeviren, M. (2010). A hybrid multi-criteria decision-making model for personnel selection in manufacturing systems. In Journal of Intelligent Manufacturing (Vol. 21, Issue 4, pp. 451460). https://doi.org/10.1007/s10845-008-0200-7

Demir, K., \& Çalık, E. (2020). İşgören Seçiminde İnsan Kaynakları Analitiği (İKA) Yaklaşımının Kullanilmas1 (The Use of Human Resources Analytics Approach in Employee Selection). Journal of Business Research - Turk, 12(4), 3747-3758. https://doi.org/10.20491/isarder.2020.1070

Demirci, A. E., \& Kılıç, H. S. (2019). Personnel Selection Based on Integrated Multi-Criteria Decision Making Techniques. International Journal of Advances in Engineering and Pure Sciences, 2, 163-178. https://doi.org/10.7240/jeps.505970

Heidary Dahooie, J., Beheshti Jazan Abadi, E., Vanaki, A. S., \& Firoozfar, H. R. (2018). Competency-based IT personnel selection using a hybrid SWARA and ARAS-G methodology. In Human Factors and Ergonomics In Manufacturing (Vol. 28, Issue 1, pp. 516). https://doi.org/10.1002/hfm.20713

Isson, J. P., \& Harriott, J. S. (2016). People Analytics in the Era of Big Data-Changing the Way You Attract, Acquire, Develop, and Retain Talent. John Wiley \& Sons.

Jain, N., Tomar, A., \& Jana, P. K. (2021). A novel scheme for employee churn problem using multi-attribute decision making approach and machine learning. Journal of Intelligent Information Systems, 56(2), 279-302. https://doi.org/10.1007/s10844-020-00614-9

Jantan, H., Hamdan, A. R., \& Othman, Z. A. (2009). Potential data mining classification techniques for academic talent forecasting. In ISDA 2009 - 9th International Conference on Intelligent Systems Design and Applications (pp. 1173-1178). https://doi.org/10.1109/ISDA.2009.64

Jantan, H., Hamdan, A. R., \& Othman, Z. A. (2011). Talent knowledge acquisition using data mining classification techniques. In Conference on Data Mining and Optimization (pp. 32 37). https://doi.org/10.1109/DMO.2011.5976501

Jasemi, M., \& Ahmadi, E. (2018). A new fuzzy ELECTRE-based multiple criteria method for personnel selection. In Scientia Iranica (Vol. 25, Issue 2E, pp. 943-953). https://doi.org/10.24200/sci.2017.4435

Kenger, M. D., \& Organ, A. (2017). Banka Personel Seçiminin Çok Kriterli Karar Verme Yöntemlerinden Entropi Temelli ARAS Yöntemi İle Değerlendirilmesi. In Adnan Menderes Üniversitesi Sosyal Bilimler Enstitüsü Dergisi (Vol. 4, Issue 4, pp. 152-170). https://doi.org/10.30803/adusobed.336215

Koyuncu, O., \& Özcan, M. (2014). Personel Seçim Sürecinde Analitik Hiyerarşi Süreci ve TOPSIS Yöntemlerinin Karş1laştırılması: Otomotiv Sektöründe Bir Uygulama. Hacettepe Üniversitesi İktisadi ve İdari Bilimler Fakültesi Dergisi, 32(2). https://doi.org/10.17065/huiibf.14332

Krishankumar, R., Premaladha, J., Ravichandran, K. S., Sekar, K. R., Manikandan, R., \& Gao, X. Z. (2020). A novel extension to VIKOR method under intuitionistic fuzzy context.pdf. Soft Computing 2020, 24(2), 1063-1081.

Kuşakçı, A. O., Ayvaz, B., Öztürk, F., \& Sofu, F. (2019). Bulanik Multimoora ile Personel Seçimi: Havacılık Sektöründe Bir Uygulama. Ömer Halisdemir Üniversitesi Mühendislik Bilimleri Dergisi. https://doi.org/10.28948/ngumuh.516835 
Li, Y.-M., Lai, C.-Y., \& Kao, C.-P. (2011). Building a qualitative recruitment system via SVM with MCDM approach. Applied Intelligence, 35(1), 75-88. https://doi.org/10.1007/s10489009-0204-9

Maghsoodi, A. I., Riahi, D., Herrera-Viedma, E., \& Zavadskas, E. K. (2020). An integrated parallel big data decision support tool using the W-CLUS-MCDA: A multi-scenario personnel

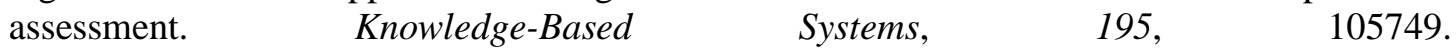
https://doi.org/10.1016/j.knosys.2020.105749

Momin, W. Y. M., \& Mishra, K. (2015). HR Analytics as a Strategic Workforce Planning Weena. International Journal of Applied Research, 1(4), 258-260.

Özdemir, Y., \& Nalbant, K. G. (2018). A Real Personnel Selection Problem Using the Generalized Choquet Integral Methodology. In Business \& Management Studies: An International Journal (Vol. 6, Issue 2). https://doi.org/10.15295/bmij.v6i2.270

PERYÖN. (2018). Çalışan Devir Oranı Araştırması Sonuç Raporu.

Pessach, D., Singer, G., Avrahami, D., Chalutz Ben-Gal, H., Shmueli, E., \& Ben-Gal, I. (2020). Employees recruitment: A prescriptive analytics approach via machine learning and mathematical programming. Decision Support Systems, 134, 113290. https://doi.org/10.1016/j.dss.2020.113290

Putra, M. G. L., Ariyanti, W., \& Cholissodin, I. (2016). Selection and Recommendation Scholarships Using AHP-SVM-TOPSIS. Journal of Information Technology and Computer Science, 1(1), 1-13.

Salehi, K. (2016). An Integrated Approach of Fuzzy AHP and Fuzzy VIKOR for Personnel Selection Problem. Global Journal of Management Studies and Researches, 3(3), 89-95.

Shehu, M. A., \& Saeed, F. (2016). An Adaptive Personnel Selection Model For Recruitment Using Domain-Driven Data Mining. Journal of Theoretical and Applied Information Technology, 91(1), 117-130.

Shehu, V., \& Besimi, A. (2018). Improving employee recruitment through data mining. In Á. Rocha, H. Adeli, L. P. Reis, \& S. Costanzo (Eds.), Advances in Intelligent Systems and Computing (Vol. 745, pp. 194-202). Springer International Publishing. https://doi.org/10.1007/978-3-319-77703-0_19

Wang, G., Liu, L., Peng, Y., Nie, G., Kou, G., \& Shi, Y. (2010). Predicting credit card holder churn in banks of China using data mining and MCDM. In Proceedings - 2010 IEEE/WIC/ACM International Conference on Web Intelligence and Intelligent Agent Technology - Workshops, WI-IAT 2010 (pp. 215-218). https://doi.org/10.1109/WI-IAT.2010.237

Yıldırım, B. I., Uysal, F., \& Ilgaz, A. (2019). Havayolu işletmelerinde personel seçimi: ARAS yöntemi ile bir uygulama. In Süleyman Demirel Üniversitesi Sosyal Bilimler Enstitüsü Dergisi (Vol. 2, Issue 33, pp. 219-231).

Zhang, S., \& Liu, S. (2011). A GRA-based intuitionistic fuzzy multi-criteria group decision making method for personnel selection. Expert Systems with Applications, 38(9), 11401-11405. https://doi.org/10.1016/j.eswa.2011.03.012 